included myxoedema, hyperthyroidism, diabetes, pyelonephritis and nephritis, cardiac failure, pernicious anaemia, lymphatic leukaemia, myelogenous leukaemia, cerebral tumour, pneumonia, bronchial asthma, chorea, polyarthritis, gastritis, chronic diarrhoea, and leucoplakia. Of these twenty-three patients seventeen were receiving daily doses of orange juice and the remaining six were consuming potatoes daily, with tomatoes and other vegetables and fruits, and occasional quantities of orange juice. These patients gave the following results:

$$
\begin{aligned}
& 6 \text { gave no petechiae } \\
& 5 \text { " } 1 \text { petechia } \\
& 3 \text { " } 2 \text { petechiae } \\
& 1 \text { " } 3 \text { " } \\
& 2 " 4 \quad 4 \quad
\end{aligned}
$$$$
\begin{array}{llcc}
2 & \text { gave } & \multicolumn{3}{c}{\text { petechiae }} \\
1 & \Rightarrow & 7 & \\
1 & \prime & 10 & " \\
1 & \Rightarrow & 14 & " \\
1 & \# & 68 & \#
\end{array}
$$

Total : 22 patients gave 63 petechiae. (The last patient was suffering from myelogenous leukaemia, and, since capillary fragility is well known in such cases irrespective of diet, his case was not used in computing totals or averages.) The average number of petechiae was 2.86 . Statistical analysis showed that this was not significantly diferent from the normal average. 14 per cent. gave between foun

\section{Discussion of Results}

The question of the age of patients requires consideration, although Göthlin has produced evidence that even great age does not significantly affect the capillary resistance. It may, however, prove of interest to give the average age of the groups under consideration. The age averages were: gastric ulcer cases, 48.6 years ; duodenal ulcer cases, 42.3 years; various diseases, 46.7 years. It was not possible to obtain the actual ages of all the normals investigated, but an estimated average is 22 to 25 years. It is apparent that the normal group is not completely comparable with the diseased group. Nevertheless the fact that the age averages of the other three groups are approximately the same provides a satisfactory check upon any possible influence of age. As regards sex, twelve out of twenty-eight gastric ulcer cases were female ; only one out of fourteen duodenal ulcer patients was a female. Thirteen out of the "various diseases" group were female, and thirteen out of the twenty-two normals were female. With the exception of the duodenal ulcer cases, therefore, the distribution between the two sexes was fairly even.

It appears from the above that the lowering of the capillary resistance in cases of gastric ulcer is traceable directly to deficiency of antiscorbutic vitamins in the diet. The results were not of such a clear-cut nature in the duodenal ulcer cases, but nevertheless there appears little doubt that those cases which have been for more than ten days on the dietary regimen usually prescribed show a definite increase in capillary fragility, unless the diet has been supplemented with some potent source of antiscorbutic vitamins.

The genesis of peptic ulcer could not be correlated definitely with deficiency of antiscorbutic vitamins in the diet, but the possibility that it may play a part in some cases cannot be excluded. It seems more likely that the deficiency of antiscorbutic vitamins in the therapeutic diet may be a factor influencing the transition from the acute to the chronic condition, predisposing to delay in healing, relapses, and possibly haematemesis, but of this we have at present no definite proof.

It is of interest to note that many of these patients said that before the onset of their complaint they had no liking for fresh fruit, salads, or green vegetables, but all who expressed this dislike asserted that they were very fond of potatoes. This appears to be an interesting example of compensatory selection of diet.

\section{Summary and Conclusions}

1. Eighty-seven subjects have been examined by Göthlin's capillary fragility method. These subjects included patients with gastric and duodenal ulcer, cases of various diseases, and normal people of both sexes.

2. Hospital patients on a dietary regimen for gastric or duodenal ulcer showed a degree of capillary fragility significantly greater than normal subjects or patients suffering from other diseases.

3. Examination of the records of the patients indicates that the degree of capillary fragility is related to inadequacy of the diet in respect of antiscorbutic vitamins.

4. No evidence was obtained from the records that the development of peptic ulcer was conditioned by deficiency of antiscorbutic vitamins in the diet.

I wish to express my thanks to W. A. Carr Fraser, D.Sc., B.V.Sc., F.S.S.Lond., statistician to the Nutrition Council of the Commonwealth of Australia, for the statistical analysis of the data. I am also indebted to Professor Lambie for help and advice; and to the medical superintendents and resident medical officers of the Royal Prince Alfred Hospital, the Sydney Hospital, the Prince Henry Hospital, and the North Shore Hospital for their assistance in obtaining peptic ulcer patients.

\section{REFERENCES}

Archer and Graham (1936). Lancet, 2. 364.
Bentsáth, A., Rusznyák, St., and Szent-Györgyi, A. (1936). Nature, 138,798

Falk, G., Gedda, K. O., and Göthlin, G. F. (1932). Skand. Arch. Physiol., 65, 24.

Göthlin, G., F. (1931). Ibid., 61, 225.

Harris, L. J., Abbasy, M. A., Ray, S. N., and Marrack, J. R. (1935). Lancet, 2, 1399. (1936a). Ibid., 1, 966.

- $\quad$ and Yudkin, J. (1936b). Ibid., 1, 1488.

Troutt, L. (1932). J. Amer. Dietet. Ass., 8, 25.

\section{PROPHYLACTIC USE OF SULPHONAMIDE PREPARATIONS IN OBSTETRIC PRACTICE}

\author{
BY
}

\section{R. W. JOHNSTONE, C.B.E., M.D., F.C.O.G. Professor of Midwifery and Diseases of Women, Edinburgh University}

At the end of 1936 my colleagues at the Royal Maternity and Simpson Memorial Hospital and I were approached by Bayer Products Ltd., the manufacturers of prontosil, and by Messrs. May and Baker, the manufacturers of proseptasine, with a request to try the effect of their products prophylactically. The amount of work to be overtaken by a limited resident staff in the hospital is so great that no investigation on strictly scientific lines and requiring much additional clerical work could be contemplated; but we agreed to make a rough-and-ready clinical experiment on a large scale by administering one or other of these drugs to every patient in the early days of her puerperium over the whole period of one year. The results of that year's work compared with those of previous years would afford reasonable ground for forming an opinion as to the efficacy or otherwise of the sulphonamide preparations in preventing the occurrence of puerperal infection.

\section{The Routine}

In order to obtain approximately equal numbers under each drug all women admitted on Monday, Wednesday, and Friday and each alternate Sunday were given prontosil after delivery; those admitted on the other days were 
given proseptasine. The drugs, which were supplied by the makers free of charge for the purpose of this test, were prontosil album ( $p$-aminophenylsulphonamide) in 5 -grain tablets and proseptasine ( $p$-benzylaminophenylsulphonamide) in $7 \frac{1}{2}$-grain tablets.

The routine was that each patient received two tablets three times a day for the first four days after delivery, and then one tablet three times a day until the end of the seventh day. The prontosil group therefore received in general a total of 165 grains of prontosil album in the course of seven days, while the proseptasine group received $247 \frac{1}{2}$ grains of proseptasine in the same period. One qualification must be mentioned-namely, that rather less than a half of the prontosil group received only one tablet three times a day for the whole seven days. This reduced dose was given to his patients on the request of one member of the staff, who had observed toxic symptoms elsewhere when the larger dose had been administered.

In all cases in which there was a clear probability of uterine infection a more intensified treatment was given, the soluble form of sulphonamide being injected intramuscularly in addition to the oral administration as above mentioned. Such cases included "failed forceps" outside hospital, acute pyrexia early in the puerperium, and cases of septic abortion. The drugs given intramuscularly were prontosil soluble in 2.5 per cent. solution, supplied in $10-\mathrm{c} . \mathrm{cm}$. ampoules, and soluseptasine in 5 per cent. solution, supplied in 10-c.cm. ampoules. The routine of using drugs by injection was as follows: Prontosil soluble was given in an initial dose of $20 \mathrm{c.cm}$. followed by four doses of $10 \mathrm{c.cm}$. each at four-hourly intervals-a total of $60 \mathrm{c.cm}$. Soluseptasine was given in an initial dose of $10 \mathrm{c} . \mathrm{cm}$. followed by three doses of $10 \mathrm{c} . \mathrm{cm}$. each at four-hourly intervals-a total of $40 \mathrm{c.cm}$. In most potentially infected cases an injection course was begun within a few hours of delivery, and in one or two instances the first dose was actually given before delivery.

\section{Toxic Effects}

There were remarkably few cases in which any toxic effects of the drugs were observed. The most frequent and obvious toxic sign was cyanosis, which occurred in cases of the routine oral administration but proportionately more often where the oral administration was being supplemented by injections. The only other sign or symptom which we noticed at all frequently was a slight drowsiness. There were no cases of marked anaemia induced by the drugs or of acidosis. During the year numerous cases of diarrhoea with nausea or vomiting occurred. Although such symptoms have been reported as following sulphonamide administration it seems unlikely that any of these cases can be attributed to the use of the drugs, because a mild form of gastro-enteritis had been prevalent among the patients and staff in the hospital for two years or more. Mild albuminuria, another reported toxic sign, was not observed, and cases of toxaemia of pregnancy with occasionally massive albuminuria before delivery showed no abnormal persistence of albumin in the urine after delivery. There were no cases of skin eruption. Some cases with normal labour and spontaneous delivery manifested a persistently frequent pulse (90 to 110) during the puerperium without any other morbid signs. It was suggested that this might be the result of the drugs, but we had no clear evidence either for or against the suggestion.

Magnesium sulphate was not given by mouth at the same time as any sulphonamide preparation. If it became necessary to administer it the sulphonamide was stopped.
Ferrous sulphate was frequently administered at the same time as the sulphonamide drugs and, as might be expected. gave rise to no appreciable abnormal symptoms.

\section{Results of Year's Working}

The results of last year's working may be summarized and compared with previous years thus:

1. Local Uterine Infection; that is, Cases with One or More of the Following Symptoms-Offensive Lochia, Uterine Tenderness, Delaved Involution, and no Other Recognizable Cause of Temperature if Pyrexia was Present.

\begin{tabular}{c|c|c|c}
\hline 1934 & 1935 & $1936^{*}$ & 1937 \\
\hline $\begin{array}{c}165 \text { cases out } \\
\text { of } 1991 \\
(8.2 \%)\end{array}$ & $\begin{array}{c}193 \text { cases out } \\
\text { of } 2.016 \\
(9.5 \%)\end{array}$ & $\begin{array}{c}150 \text { cases out } \\
\text { of } 2.188 \\
(6.7 \%)\end{array}$ & $\begin{array}{c}139 \text { cases out } \\
\text { of } 2.241 \\
(6.2 \%)\end{array}$ \\
\hline
\end{tabular}

* Throughout 1936 a similar experiment was carried out with calcium sulphide Every patient received three grains of the drug thrice daily from the day of delivery until she left hospital.

II. Morbid Puerperia (B.M.A. Standard) due to Uterine Infection

\begin{tabular}{c|c|c|c}
\hline 1934 & 1935 & 1936 & 1937 \\
\hline $\begin{array}{c}77 \\
(3.8 \%)\end{array}$ & $\begin{array}{c}74 \\
(3.6 \%)\end{array}$ & $\begin{array}{c}67 \\
(3.06 \%)\end{array}$ & $\begin{array}{c}44 \\
(1.9 \%)\end{array}$ \\
\hline
\end{tabular}

During 1937 forty-seven patients in all were transferred to the City Fever Hospital as being frankly infected. Of these, two died (both of pneumonia after many weeks' illness). All but five of the forty-seven had been long enough in hospital to have received a more or less complete course of sulphonamide before transfer. In only five of the transferred cases was a positive culture of haemolytic streptococci obtained after removal to the City Hospital, but these were not the five who had been transferred too early to have received the routine sulphonamide treatment. In forty-nine cases out of the 139 local uterine infections high vaginal swabs were taken and sent to Dr. C. A. Green of the Bacteriological Department of Edinburgh University. Only three of these showed haemolytic streptococci, but none conformed to Lancefield's groups $\mathrm{A}-\mathrm{H}$. Of the remaining forty-six, twelve showed a culture of Bacillus coli, nine of staphylococcus, one of non-haemolytic streptococcus, and one of Bacillus proteus.

To investigate the relative efficacy of the two particular preparations of these drugs was no part of our purpose and would have involved more clerical work than we could reasonably demand of our resident staff. Our impression was that there was no appreciable difference between them either in efficacy or in toxicity, but in order to test this point briefly we analysed the first five hundred cases of 1937, with the following results, which on the whole seem to bear out the impression just stated:

\begin{tabular}{|c|c|c|c|}
\hline $\begin{array}{l}\text { Prontosil Group } \\
\text { ( } 240 \text { cases) }\end{array}$ & & $\begin{array}{c}\text { Proseptasine Group } \\
(260 \text { cases })\end{array}$ & \\
\hline 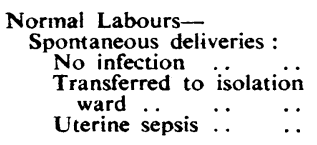 & $\begin{array}{l}93.5 \% \\
4.4 \% \\
1.2 \%\end{array}$ & $\begin{array}{l}\text { Normat Labours- } \\
\text { Spontaneous Deliveries : } \\
\text { No infection } \because . \\
\text { Transferred to isolation } \\
\text { ward ... } \ldots \\
\text { Uterine sepsis } . .\end{array}$ & $\begin{array}{r}92.1 \% \\
6.3 \% \\
1 \%\end{array}$ \\
\hline 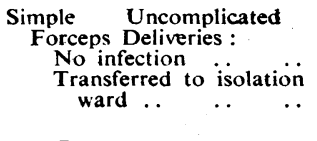 & $\begin{array}{l}82.1 \% \\
17.9 \%\end{array}$ & $\begin{array}{l}\text { Simple Uncomplicated } \\
\text { Forceps Deliveries : } \\
\text { No infection } \\
\text { Transferred to isolation } \\
\text { ward .. } . . \\
\text { Uterine sepsis } . .\end{array}$ & $\begin{array}{r}88.5 \% \\
5 .: \% \\
5 . . \%\end{array}$ \\
\hline $\begin{array}{l}\text { Other Cases, including } \\
\text { Abortion: } \\
\text { No infection } \\
\text { Transferred to isolation } \\
\text { ward . } \\
\text { Uterine sepsis }\end{array}$ & $\begin{array}{r}62.1 \% \\
29 . \% \% \\
8.6 \%\end{array}$ & 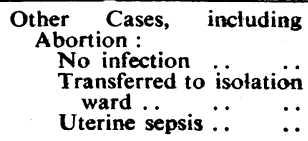 & $\begin{array}{l}59.6 \% \\
31.5 \% \\
7.1 \%\end{array}$ \\
\hline
\end{tabular}


Since September, 1936, I have been using M. \& B. 125, practically equivalent to proseptasine, at the Maternity Department of the Western General Hospital. Our intention there was to put every alternate case on prophylactic sulphonamide, but this routine has not been strictly adhered to, and there has been a tendency to select cases, the more serious ones and those more likely to be followed by infection being given the prophylactic doses. Two $7 \frac{1}{2}$-grain tablets were given four times a day for the first four days and one tablet three times a day for the next three days, so that the patients who were on this treatment received $307 \frac{1}{2}$ grains of sulphonamide in the week following delivery. No toxic symptoms of any significance or moment were observed, except in one case where a skin eruption occurred which was thought to be due to the sulphonamide medication.

Among 322 patients who received prophylactic sulphonamide there were twenty cases of morbid puerperia, but of these only six were due to local uterine infection, while one developed definite puerperal sepsis. Of 383 cases to which the sulphonamide was not given there were fifteen who showed signs of morbid puerperia, but of these again only six showed symptoms of local uterine infection, while one developed puerperal septicaemia. In this investigation, therefore, the general result seems negative.

My colleagues and I desire to express our thanks to Messrs. May and Baker and to Bayer Products Ltd. for their generosity in providing their drugs.

\section{THE EARLY OCCURRENCE OF HIGH BLOOD PRESSURE IN COARCTA- TION OF THE AORTA}

\author{
BY
}

E. JOAN ROOKE, M.B., B.S.,

(From the Department of Clinical Research, University College Hospital Medical School)

In recording high blood pressure as a regular feature of coarctation of the aorta Sir Thomas Lewis (1933) wrote: "We still lack records covering the periods of childhood and adolescence, during which seemingly very few cases are diagnosed. While it may be highly probable that coarctation means high pressure from a time shortly after birth to the time when cardiac failure supervenes, or death occurs from other cause, the gap that is still present in our evidence forbids us finally to draw the corresponding conclusion."

The youngest case then on record was a boy of 14 who had coarctation and a blood pressure of $150 \mathrm{~mm}$. systolic (Hamilton and Abbott, 1927-8). Wilkinson (1932-3) published the case of a child of 4 years whose blood pressure was $150 \mathrm{~mm}$. in the arms and who had only feeble pulsation in the iliac artery. In his case there was no evidence of anastomotic vessels. Sheldon (1932-3) published a case in the same year-that of a child of 12 in whom the blood pressure was $150 \mathrm{~mm}$. in the arms and who had evidence of collateral circulation.

\section{Case Report}

The case here recorded was seen recently. The patient was a boy of 3 years. At birth artificial respiration was required, and during the first fortnight of life he became blue very easily and was treated for this with oxygen. Afterwards he was apparently normal and able to play with other children.
His parents noticed that he became blue rather eas:ly in the cold but not at other times. On examination he was fcund to be a small but well-nourished child withcut cyanosis. His heart was enlarged, the impulse being visible $2 \mathrm{~cm}$. outsice the nipple-line in the fifth space, and the right border of cardiac dullness $1 \mathrm{~cm}$. to the right of the mid-line. Dullness to percussion was found in the first and second spaces to the left of the sternum. A systolic thrill was felt to the right of the sternum in the second space and a harsh systolic murmur maximal at this point. A systolic murmur was heard over the inner ends of all the right intercostal spaces and in the same line below the costal margin, and in the neck. A similar murmur was heard along the left border of the sternum, but it was not so extensive. These murmurs probably resulted from enlarged internal mammary arteries. The heart sounds at the apex were normal. The radial pulses were full, but neither femoral pulse could be felt, nor was there any pulsation in the posterior tibial or dorsalis pedis arteries of either leg. Anastomotic vessels were then searched for and found. There was visible pulsation from anastomot:c arteries running out of the subclavian triangle and under the anterior border of the trapezius, more prominent on the right than on the left; a thrill was felt over them on the right side. A tortuous artery was seen pulsating in the right axilla, and it could be traced from under the scapula and passing deep to the pectoral muscles. Pulsation was also found $\mathrm{cn}$ the back, in the second, fourth, and fifth right spaces, and a systolic murmur was heard over all these areas. Radiographs failed to show any erosion of the ribs. When first seen in December, 1937, the blood pressure in the right arm was $150 \mathrm{~mm}$. systolic and $85 \mathrm{~mm}$. diastolic measured by auscultation, and $140 \mathrm{~mm}$. measured by palpation. The pressure in the left arm was always about $40 \mathrm{~mm}$. lower than that in the right arm. In January, 1938, when the patient was seen again, the pressure in the right arm was $162 \mathrm{~mm}$. After resting for half an hour the pressure was $160 \mathrm{~mm}$., and after another fifteen minutes' rest it was $158 \mathrm{~mm}$. All these readings were taken with a sphygmomanometer by palpation.

\section{Commentary}

These cases help to fill the gap referred to earlier, and indicate that the blood pressure in coarctation of the aorta is high throughout life. The demonstration of high blood pressure in the child is important because it occurs at a period of life when high pressure from other cause is extremely rare. The conclusion, which may now be formed with more certainty, that high pressure is lifelong in coarctation is of value because these cases are useful in studying the effects of long-lasting high pressure of a relatively uncomplicated kind and in comparing the arteries in upper and lower limbs where they are submitted to very different pressures.

\section{REFERENCES}

Hamilton, W. F., and Abbott, M. E. (1927-8). Amer. Heart J., 3, 381

Lewis, T. (1933). Heart, 16, 205.

Sheldon, W. (1932-3). Proc. roy. Soc. Med., 26, 154.

Wilkinson, K. D. (1932-3). Ibid., 26, 1537.

The British $X$-Ray and Radium Protection Committee was formed in 1921, as the result of joint action between the Royal Society of Medicine, the Röntgen Society, the British Association for the Advancement of Radiology and Physiotherapy (now the British Institute of Radiology, incorporated with the Röntgen Society), the Institute of Physics, the London Radium Institute, and the National Physical Laboratory. The personnel of the committee was afterwards widened to include representatives from the provincial schools. Its first recommendations were issued in 1921, and these were revised in 1923, 1927, and 1934. A further revised report, dated January, 1938, has now appeared, and copies may be had from the honorary secretaries of the Protection Committee at. 32, Welbeck Street, London, W.1, or the director, National Physical Laboratory, Teddington, Middlesex. 